\title{
Patient-ventilator asynchrony in conventional ventilation modes during short-term mechanical ventilation after cardiac surgery: randomized clinical trial
}

\author{
Wagner Souza Leite, ${ }^{1}$ Alita Novaes, ${ }^{1}$ Monique Bandeira, ${ }^{1}$ Emanuelle Olympia Ribeiro, ${ }^{1}$ Alice Miranda dos Santos, \\ Pedro Henrique de Moura, ${ }^{1}$ Caio César Morais, ${ }^{2}$ Catarina Rattes, ${ }^{1}$ Maria Karoline Richtrmoc, ${ }^{1}$ Juliana Souza, ${ }^{1}$ \\ Gustavo Henrique Correia de Lima, ${ }^{1}$ Norma Sueli Pinheiro Modolo, ${ }^{3}$ Antonio Christian Evangelista Gonçalves, ${ }^{3}$ \\ Carlos Alfredo Ramirez Gonzalez, ${ }^{4}$ Maria do Amparo Andrade, ${ }^{1}$ Armèle Dornelas De Andrade, ${ }^{1}$ \\ Daniella Cunha Brandão, ${ }^{1}$ Shirley Lima Campos ${ }^{1}$
}

\author{
${ }^{1}$ Department of Physical Therapy, Universidade Federal de Pernambuco, Recife, Pernambuco, Brazil \\ ${ }^{2}$ Department of Anesthesia, Critical Care and Pain Medicine, Massachusetts General Hospital, Boston, MA, USA \\ ${ }^{3}$ Department of Anaesthesiology, Institute of Bioscience, School of Medicine, UNESP-Universidade Estadual Paulista, \\ Botucatu, São Paulo, Brazil \\ ${ }^{4}$ Hospital Monsenhor Walfredo Gurgel, Natal, Rio Grande do Norte, Brazil
}

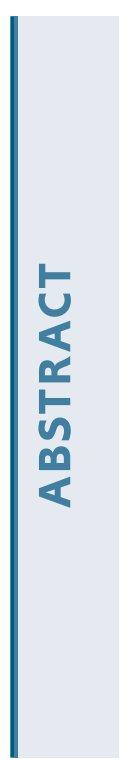

\begin{abstract}
Introduction and aim: Studies regarding asynchrony in patiients in the cardiac postoperative period are still only a few. The main objective of our study was to compare asynchronies incidence and its index (AI) in 3 different modes of ventilation (volume-controlled ventilation [VCV], pressure-controlled ventilation [PCV] and pressure-support ventilation [PSV]) after ICU admission for postoperative care.

Methods: A prospective parallel randomised trialin the setting of a non-profitable hospital in Brazil. The participants were patients scheduled for cardiac surgery. Patients were randomly allocated to VCV or PCV modes of ventilation and later both groups were transitioned to PSV mode.

Results: All data were recorded for 5 minutes in each of the three different phases: T1) in assisted breath, T2) initial spontaneous breath and T3) final spontaneous breath, a marking point prior to extubation. Asynchronies were detected and counted by visual inspection method by two independent investigators. Reliability, inter-rater agreement of asynchronies, asynchronies incidence, total and specific asynchrony indexes (AIt and $\mathrm{AI}_{\text {specific }}$ ) and odds of $\mathrm{AI} \geq 10 \%$ weighted by total asynchrony were analysed. A total of 17 patients randomly allocated to the VCV $(n=9)$ or PCV $(n=8)$ group completed the study. High inter-rated agreement for $\mathrm{AI}_{\mathrm{t}}\left(\mathrm{ICC} 0.978 ; \mathrm{IC}_{95} \%, 0,963-0.987\right)$ and good reliability $(\mathrm{r}=0.945 ; p<0.001)$ were found. Eighty-two $\%$ of patients presented asynchronies, although only $7 \%$ of their total breathing cycles were asynchronous. Early cycling and double triggering had the highest rates of asynchrony with no difference between groups. The highest odds of AI $\geq 10 \%$ were observed in VCV regardless the phase: OR 2.79 (1.36-5.73) in T1 vs T2, $p=0.005$; OR 2.61 (1.27-5.37) in T1 vs $\mathrm{T} 3, p=0.009$ and OR 4.99 (2.37-10.37) in T2 vs T3, $p<0.001$.

Conclusions: There was a high incidence of breathing asynchrony in postoperative cardiac patients, especially when initially ventilated in VCV. VCV group had a higher chance of $\mathrm{AI} \geq 10 \%$ and this chance remained high in the following PSV phases.
\end{abstract}

Key words: Ventilator weaning; thoracic surgery; breath triggering; cycle synchrony.

Correspondence: Wagner Souza Leite, Universidade Federal de Pernambuco, Av. Prof. Moraes Rego 1235, Cidade Universitária, Recife - PE, 50670-901, Brazil. Mobile:+55.81.979098830. E-mail: wagnerszleite@gmail.com

Contributions: WSL, data curation, investigation, project administration, visualization, formal analysis, roles/writing, original draft; $\mathrm{AN}$, data curation, investigation, roles/writing, original draft; MB, formal analysis, visualization; EOR, MKR, JS, methodology, investigation; AMdS, investigation, roles/writing, original draft; PHdM, methodology, investigation; CCM, CR, visualization, formal analysis; GHCdL, CARG, methodology, roles/writing, original draft; NSPM, validation, writing, review and editing; ACEG, methodology, formal analysis; MdAA, methodology, investigation, writing, review and editing; ADDA, supervision, validation, writing, review and editing; DCB, supervision; validation, writing, review and editing; SLC, conceptualization, methodology, validation, writing, review and editing.

Competing interests: The authors declare that they have no competing interests.

Funding: This research did not receive any specific grant from funding agencies in the public, commercial, or not-for-profit sectors.

Availability of data and materials: The data that support the findings of this study are available from Wagner Souza Leite but restrictions apply to the availability of these data, which were used under license for the current study, and so are not publicly available. Data are however available from the authors upon reasonable request and with permission of Wagner Souza Leite.

Ethics approval and consent to participate: The study was approved by local clinical research ethics committee (Hospital of Recife, Brazil) by protocol 1,928,293 and registered at ClinicalTrials.gov (NCT03141216). All patients provided written informed consent before surgery.

Consent for publication: All patients provided written informed consent before surgery.

Trial registration: Clinical Trials NCT03141216 (date of registration: February 21, 2017). 


\section{Introduction}

Patients in the postoperative period of cardiac surgery still are under invasive mechanical ventilation usually due to remaining sedative effect, but expected to be extubated in a few hours for a shorter ICU stay and better outcomes [1,2]. Skills in mechanical ventilation and respiratory monitoring should be harnessed in order to reduce patient-related risks associated with cardiac surgery such as delirium [3-5], acute respiratory distress syndrome (ARDS) with consequent comorbidities [6-8]; ventilator-related risks, such as prolonged dependence, pneumonia, and asynchrony, and as well as to reverse postoperative complications, namely, atelectasis, pneumonia and respiratory failure [9].

Ventilator-associated events and respiratory complications are negative outcomes with potential for morbidity and mortality [911], patient-ventilator asynchrony being one of them [12]. Patientventilator asynchrony is the imbalance between the patient's ventilatory demand and the offer of assistance by the ventilator $[13,14]$, that without the possible resolution can also contribute to lung injury [15], weaning delay, higher rate of tracheostomy and longer hospital stay $[12,16,17]$.

Regarding studies with asynchrony in patients in the cardiac postoperative period, only two were identified in the literature. The first evaluated the occurrence of self-triggering asynchrony in adults ventilated to the mode (SIMV) synchronized intermittent mandatory ventilation [18], while the second described a pediatric case report of difficult ventilatory weaning with gastric distention due to asynchrony [19]. Thus, it is noted that the occurrence of asynchrony may be related to adverse clinical consequences and that it needs important attention in clinical practice.

Asynchronies have been reported to occur in $25 \%$ to $100 \%$ of patients regardless of the mode of mechanical ventilation [12,2022]. Studies concerning the behavior of asynchrony, frequencies and associated outcomes are important to distinguish whether there is a difference in the patterns of asynchrony depending on the patient's clinical profile, its degree of incidence and what risks they may represent. The purpose of this study is to explore the presence of asynchrony in post-operative cardiac patients and what impact on outcomes can be observed.

The literature on patient-ventilator asynchrony in patients in the immediate cardiac postoperative period and its clinical impacts is still limited. Understanding the behavior of these events in the population addressed in this study is important for clinical implications regarding the proper management to ensure greater safety in patient care and, thus, minimize clinical deteriorations related to assistance with invasive mechanical ventilation. Thus, our study proposed:

- $\quad$ to evaluate the reliability of the visual inspection method for detecting asynchrony by flow curves, airway pressure and volume;

- to calculate the incidence of patient-ventilator asynchrony and compare the rate of asynchrony in assist-controlled volume or pressure modes and in support pressure mode.

\section{Methods}

This parallel clinical trial was carried out in the post-surgical cardiothoracic ICU of a hospital in Recife (Brazil), from March to December 2017. The study received approval by the institutional ethics committee (number 1.928.293) and registered at ClinicalTrials.gov (NCT03141216). All volunteers signed a consent form as a pre-requisite to be included in the study.

\section{Patients}

Adult patients were included, aged 18 to 65 years, with BMI between 18.5 and $29.9 \mathrm{~kg} / \mathrm{m}^{2}$ in order to avoid heterogeneous pulmonary mechanics bias imposed by adiposity of patients above that limit, and under mechanical ventilation in the immediate postoperative care. They were also required to have had a cardiac surgery with cardiopulmonary bypass, whose specific condition is associated with the risk of deficit of gas diffusion through the alveolar-capillary barrier. Cardiopulmonary bypass may activate proinflammatory cells in the body system after blood exposure to the bio-incompatible surface of the artificial blood circulation [23].

Patients with a history of chronic lung disease, neuromuscular, and/or thoracic deformity were excluded from the trial. Patients were removed from analysis if their MV weaning period was above $12 \mathrm{~h}$, since there is evidence that intubation time exceeding this threshold is associated with worse outcomes [24,25] such as delirium, acute kidney injury [26-28], higher risk of mortality, major complications and longer hospital stay [25], thereby affecting an homogeneous sampling, or graphic signals of pressure, flow and volume curves with changes in their quality by artifacts that limited the detection power, which hinders the asynchrony detection by the visual inspection method.

\section{Protocol}

The generation of the random envelope allocations was performed by an independent third party. The patients were assigned to either an initial ventilation at either VCV (volume-controlled ventilation) or PCV (pressure-controlled ventilation). As their respiratory drive and level of consciousness improved, the patients of both assisted breaths groups were transitioned to pressure support (PSV) mode prior to extubation. The entire protocol is described in the Supplementary Material.

\section{Outcomes measurement}

The following patient data were registered: sex, age, EuroScore II, time of postoperative MV, type of cardiac surgery, use of intra- and postoperative drugs, extracorporeal circulation time, and comorbidities.

All patients had 5 min of pressure, volume and flow waveforms recordings in 3 different phases, representing the $\mathrm{T}$ phases. The asynchronies identified for analysis were defined accordingly to the descriptions in Figure 1, based on the definitions set by Dres et al. and Wit et al. [22,29].

As set forth by Thille et al. [20], asynchrony index greater than or equal to $10 \%$ is a measure of severity (see eq. A1 in the Supplementary material). This cutoff point is due to the greater association with mortality risk. Thus, we pre-defined this cutoff value for considering asynchrony level as severe. In addition, heart rate (HR), blood pressure (BP), expiratory tidal volume (VTe), respiratory rate $(\mathrm{RR})$, peripheral oxygen saturation $\left(\mathrm{SpO}_{2}\right), \mathrm{pH}$, arterial partial pressure of oxygen $\left(\mathrm{PaO}_{2}\right)$, arterial partial pressure of carbon dioxide $\left(\mathrm{PaCO}_{2}\right)$, and $\mathrm{PaO}_{2} / \mathrm{FiO}_{2}$ ratio were measured.

\section{Data analysis}

Waveforms data were extracted from the electrical impedance tomography (EIT) and processed off-line in a specific software run on Labview 9.1 platform (National Instruments, Austin, TX, USA). A simultaneous analysis of the three pressure, volume and flow waveforms was performed and repeated by two independent evaluators, blinded to clinical data and interventions assigned to each participant. Several analyses were possible by visual inspection method, see attached in the Supplementary Material.

The identification of asynchrony was made by two researchers trained by extended education in study group of intensive care 
topics in an educational institution. Some of the topics discussed were modes of mechanical ventilation, analysis of ventilator graphics and respiratory and hemodynamic monitoring in a critical care unit.

\section{Sample size}

The dimensioning of the sample size was performed from a pilot study with 9 patients $(\mathrm{VCV}=5 ; \mathrm{PCV}=4)$, using GPower v. 3.0 software. For the calculation, $\alpha=0.05, \beta=0.80$ were used, and the means and standard deviations of the asynchrony index in the assist-controlled ventilatory phase in VCV (17.20 $\pm 5.35 \%)$ and PCV $(9.7 \pm 2.34 \%)$. As a result, with an effect size of $1.80,6$ participants per group would be needed. As a precautionary measure, a loss rate of $30 \%$ was added, thus, it was estimated that in view of a small variability in the results, the sample would be composed of at least 16 patients.

\section{Statistical analysis}

Some analyses were performed based on the number of individuals $\left(\mathrm{n}_{\text {individuals }}=17\right)$ and others on the number of cases, which is equivalent to the pool effect of individuals repeated in three ventilatory phases $\left(\mathrm{n}_{\text {cases }}=51\right)$.

Quantitative variables were compared by the Man-Whitney test and categorized by Pearson's Chi-square test. The analysis of ventilation and oxygenation monitoring parameters and the quantitative data were distributed by phases to each group. Based on the number of individuals, the inter-group and inter-phase analysis were performed using the Anova two-factor test.

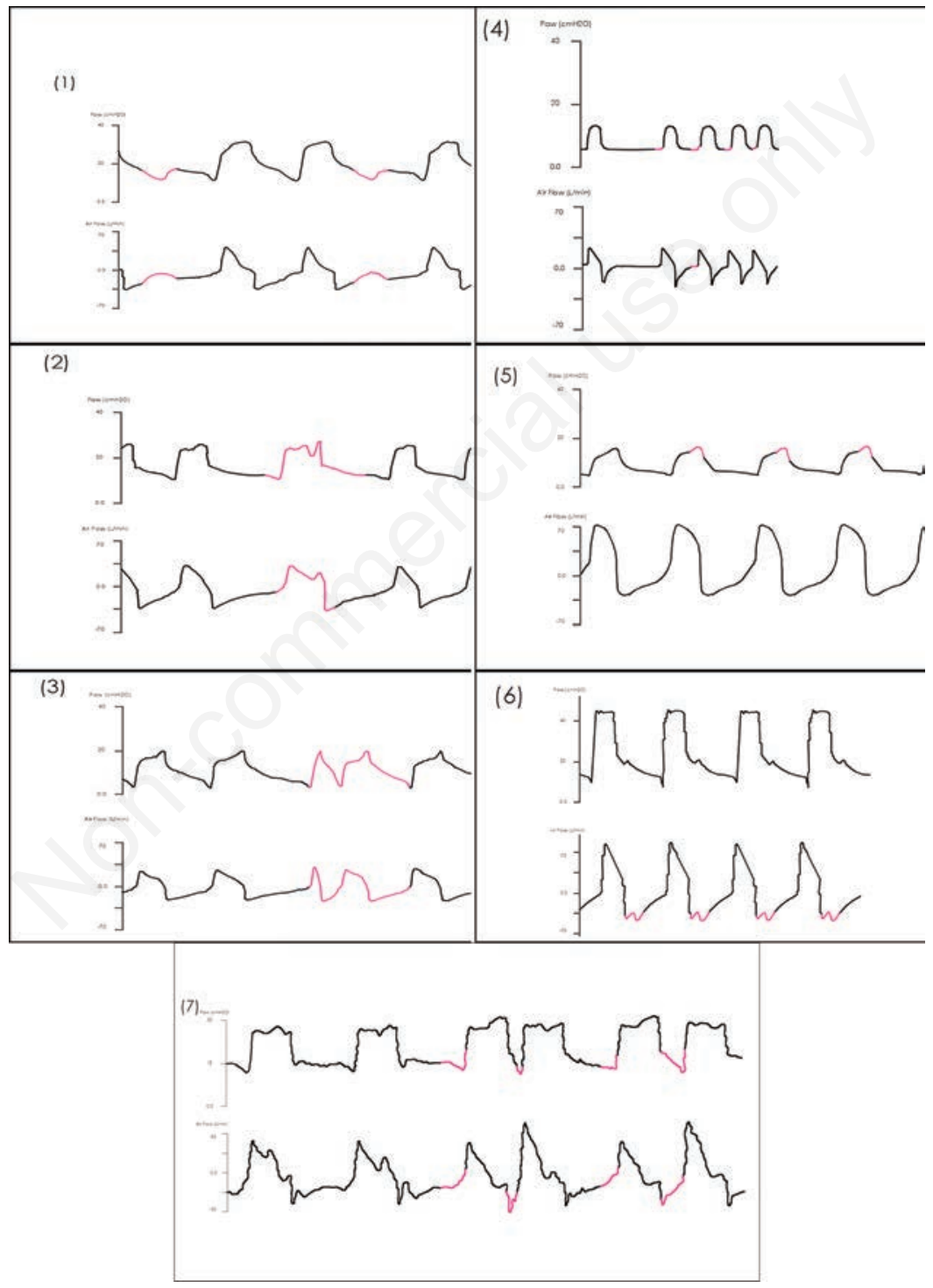

Figure 1. Definition to identify patient-ventilator asynchrony types. 1) Ineffective effort during expiration - a drop in the pressure curve during expiration and simultaneous increase in the expiratory branch of the flow curve (after $50 \%$ of the expiratory curve) insufficient to start a new cycle. 2) Ineffective effort during inspiration - a drop in the inspiratory phase pressure curve simultaneously with a fall in the flow curve also in the inspiratory phase. 3) Double triggering - two consecutive inspiratory efforts without adequate expiratory time. 4) Auto-triggering - start of the flow and pressure waveforms not preceded by a drop at the beginning of the pressure waveform indicating triggering induced by the patient. 5) Late cycling -peak at the end of the pressure waveform plateau (overshoot) before turning to exhalation. 6) Early cycling - a peak in the beginning of the expiratory branch of the flow waveform or occurring in less than $50 \%$ of the expiratory curve; 7) Reverse triggering - two consecutive breaths, the first one being ventilator-driven and the following being patient-respondent to the first breath. 
The reliability of the visual inspection method and inter-rater agreement were tested respectively by Spearman correlation and intraclass correlation (ICC) of single measures with two-way mixed model and absolute agreement set for the variables of the total number of asynchrony and AIt. We determined an ICC higher than 0.60 as acceptable [30].

The odds of $10 \%$ or higher were expressed as odds ratios (OR) by Cochran-Mantel Haenzel test in different scenarios (see Supplementary Material). All tests were two-tailed with $p<0.05$ considered significant and analyzed with SPSS software (ver. 20.0 for Windows, IBM Corp., USA).

\section{Results}

Out of 160 patients enrolled and scheduled for cardiac surgery, 17 completed the study ( 9 in the VCV group and 8 in the PCV group). Figure 2 depicts the participant flowchart.

\section{Analysis of results on $\mathbf{N}_{\text {individuals }}$}

Their mean age was $53 \pm 10.9$ years (ranging from 21 to 65 years), with over weight (BMI $27.7 \pm 2.5 \mathrm{~kg} / \mathrm{m}^{2}$ ) and $60 \%$ of them were men. Most patients underwent myocardial revascularization (58.8\%), nine of whom were ventilated in VCV and eight, in PCV modes. They presented respiratory and hemodynamic stability and a low mortality risk by EuroScore II classification [31] (Table 1).

The dosages of neuromuscular blocking (NMB) drugs, opioids, general and local anesthetics administered to patients during the intraoperative period were similar for both groups. Opioids and sedatives in the postoperative period were seldom administered (Table 1).

The variables of expired tidal volume, respiratory rate, inspiratory time, $\mathrm{pH}$, and partial pressure of carbon dioxide remained within normal range, and oxygenation with $\mathrm{PaO}_{2} / \mathrm{FiO}_{2}$ ratio above 200. There were no statistical differences in the comparative analysis between the VCV vs PCV groups for these variables. The inspiratory times in phases $\mathrm{T} 2$ and $\mathrm{T} 3$ in spontaneous ventilation were

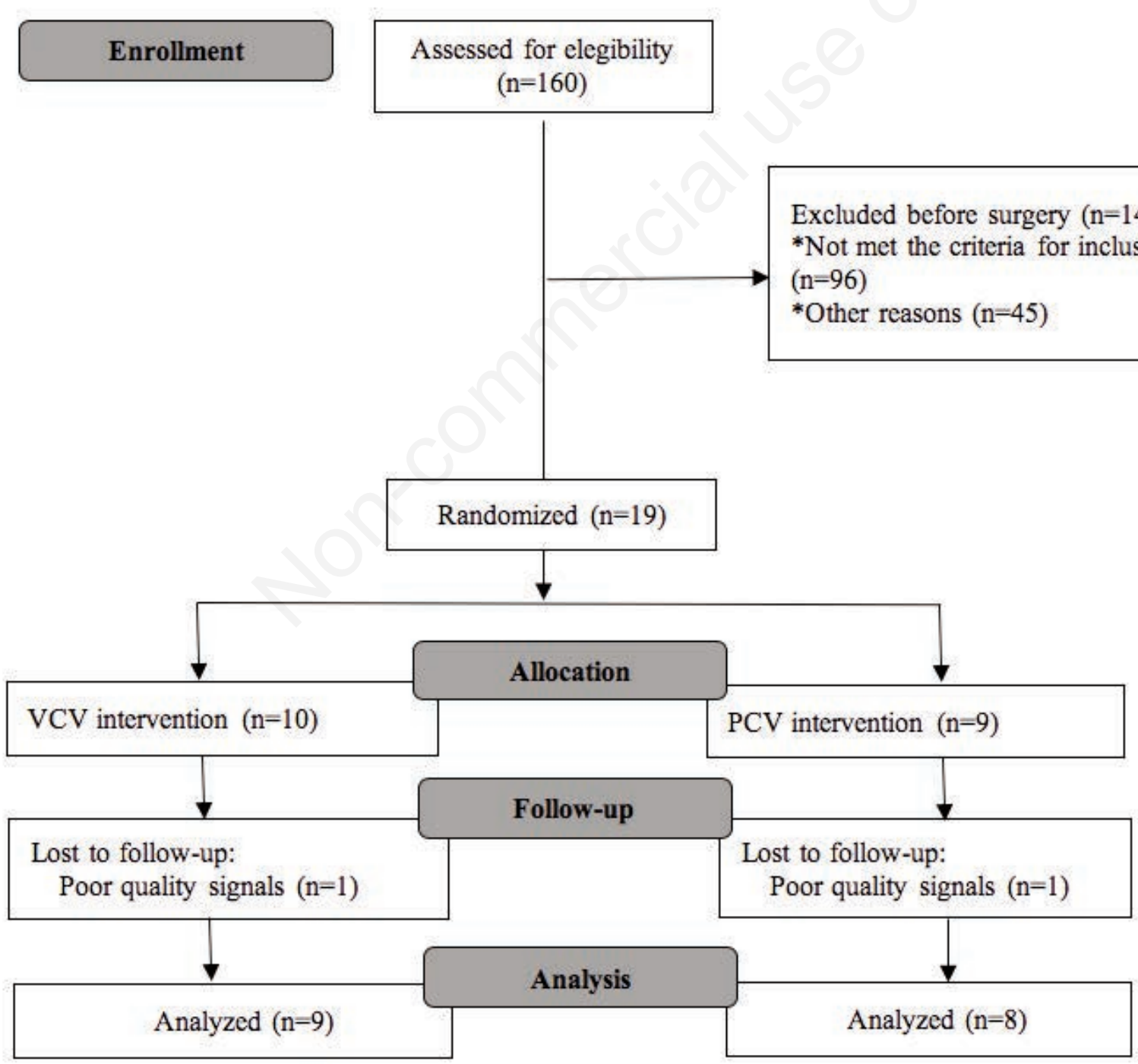


higher than during assist-controlled ventilation (both, $p<0.0001$ ), but this did not influence the analysis of the group-phase interaction (Table 2).

The results of the inter-rater reliability analysis for the total number of asynchronies $(\mathrm{r}=0.948, p<0.001)$ and asynchrony indexes $(\mathrm{r}=0.945 ; p<0.001)$ detected by the visual inspection method between two independent evaluators presented a strong correlation. The agreement was also shown to be high for the total number of asynchronies 0.98 (95\% CI 0.965-0.988) and asynchrony index 0.978 (CI 95\% 0.963-0.987) between the values estimated by both evaluators. Fourteen patients $(82.3 \%)$ presented asynchrony at some point in their assisted breathing phases. Every patient was registered at three different phases; which resulted in 51 cases of analysis. These cases made up $255 \mathrm{~min}$ of sampling recording, corresponding to 3,813 respiratory cycles, in which 267 (7\%) were deemed asynchronous.

\section{Analysis of results on $\mathbf{N}_{\text {case }}$}

Out of 51 cases, twenty-three (45.1\%) presented asynchrony at some point, occurring in fourteen $(51.9 \%)$ cases initially ventilated in VCV and nine cases (37.5\%) in PCV. The mean number of total asynchronies was $9.04(7.44 \%)$ asynchronous cycles and the $\mathrm{AI}_{\mathrm{t}}$ was $12.22(7.99 \%)$.

In comparison to PCV, VCV group scored higher indexes in all phases, although not statistically significant. The pattern of $\mathrm{AI}_{t}$ between both groups shows large difference in assist-controlled moment and that difference prospectively decreases until extubation, as seen in Figure 3. Out of the cases with asynchrony at some point in their phases $(n=23), 16$ presented severe asynchrony (AIt of $10 \%$ or higher) and 7 had AIt less than $10 \%$. There were no statistical differences in EuroScore II $(p=0.46)$, neither in the respiratory variables (Table 3 ). The asynchrony severity also showed no

Table 1. Characteristics of the patients at ICU admission.

\begin{tabular}{|c|c|c|c|c|}
\hline & General (n=17) & VCV $(n=9)$ & PCV $(n=8)$ & $p$ \\
\hline Sex (male, n/\%) & $10(58.8)$ & $6(66.7)$ & $4(50)$ & $0.49^{\mathrm{a}}$ \\
\hline Age (years) & $52.9(10.9)$ & $52(5.9)$ & $54(15.14)$ & $0.21^{\mathrm{b}}$ \\
\hline Body mass index $\left(\mathrm{kg} / \mathrm{m}^{2}\right)$ & $27.7(2.5)$ & $27.1(2.5)$ & $28.39(2.6)$ & $0.25^{\mathrm{b}}$ \\
\hline $\begin{array}{l}\text { EuroScore II (n/\%) } \\
\text { 0-2 points (low risk) } \\
\text { 3-5 points (medium risk) } \\
\geq 6 \text { points (high risk) }\end{array}$ & $\begin{array}{l}6(35.3) \\
8(47.1) \\
3(17.6)\end{array}$ & $\begin{array}{l}3(33.3) \\
4(44.4) \\
2(22.2)\end{array}$ & $\begin{array}{c}3(37.5) \\
4(50) \\
1(12.5)\end{array}$ & $0.87^{\mathrm{a}}$ \\
\hline Glasgow Coma Score (points) & $8.5(0.5)$ & $8.2(0.4)$ & $8.75(0.5)$ & $0.07^{\mathrm{b}}$ \\
\hline Mean arterial pressure (mmHg) & $80.1(13.5)$ & $78.9(14.3)$ & $81.38(13.4)$ & $0.77^{\mathrm{b}}$ \\
\hline Heart rate (bpm) & $91.4(17.4)$ & $93.7(15.1)$ & $88.88(20.5)$ & $0.34^{\mathrm{b}}$ \\
\hline $\mathrm{SaO}_{2}(\%)$ & $98.8(1.7)$ & $99.3(1.3)$ & $98.75(2.8)$ & $0.91^{\mathrm{b}}$ \\
\hline Drainage (ml) pleural & $12.5(28.9)$ & $6.3(17.7)$ & $18.75(37.2)$ & $0.49^{\mathrm{b}}$ \\
\hline Mediastinal & $73.1(76.1)$ & $59.4(46.7)$ & $87.5(99.1)$ & $0.79^{\mathrm{b}}$ \\
\hline $\begin{array}{l}\text { Surgery type }(\mathrm{n} / \%) \\
\text { Coronary artery bypass grafting } \\
\text { Heart valve replacement }\end{array}$ & $\begin{array}{l}10(58.8) \\
7(41.2)\end{array}$ & $\begin{array}{l}5(55.6) \\
4(44.4)\end{array}$ & $\begin{array}{l}5(62.5) \\
3(37.5)\end{array}$ & $0.28^{\mathrm{a}}$ \\
\hline Surgery duration (min) & $199.4(81.44)$ & $226.88(69.3)$ & $171.88(87.6)$ & $0.27^{\mathrm{b}}$ \\
\hline CPB duration (min) & $81.7(31.0)$ & $89.3(29.8)$ & $75(32.5)$ & $0.11^{\mathrm{b}}$ \\
\hline $\begin{array}{l}\text { Use of drugs (yes, } \mathrm{n} / \%) \\
\text { Intraop NMBs } \\
\text { Intraop opioids } \\
\text { Intraop general anesthesia } \\
\text { Intraop local anesthesia } \\
\text { Intraop sedatives } \\
\text { Postop opioids } \\
\text { Postop sedatives }\end{array}$ & $\begin{array}{c}13(76.5) \\
16(94.1) \\
15(88.2) \\
7(41.2) \\
11(64.7) \\
16(94.1) \\
1(5.9) \\
\end{array}$ & $\begin{array}{l}5(55.6) \\
8(88.9) \\
8(88.9) \\
4(44.4) \\
5(55.6) \\
2(22.2) \\
1(11.1) \\
\end{array}$ & $\begin{array}{l}8(100) \\
8(100) \\
7(87.5) \\
3(37.5) \\
6(75) \\
2(25) \\
0(0) \\
\end{array}$ & $\begin{array}{l}0.20 \\
1.00 \\
1.00 \\
1.00 \\
1.00 \\
1.00 \\
1.00 \\
\end{array}$ \\
\hline $\begin{array}{l}\text { Dosage of drugs (mg/ml) } \\
\text { Intraop NMBs } \\
\text { Intraop opioids } \\
\text { Intraop general anesthesia } \\
\text { Intraop local anesthesia } \\
\text { Intraop sedatives } \\
\text { Mechanical ventilation time (h) } \\
\text { Inspiratory time (s) }\end{array}$ & $\begin{array}{c}24.69(13.09) \\
20.5(19.38) \\
23.47(16.33) \\
7(9.41) \\
5(0.0) \\
5.88(2.15) \\
1.0(0.7)\end{array}$ & $\begin{array}{c}29.2(13.16) \\
18.36(18.48) \\
19.64(11.25) \\
9(9.74) \\
5(0.0) \\
5.89(2.47) \\
0.98(0.1)\end{array}$ & $\begin{array}{c}21.88(13.08) \\
22.38(21.22) \\
27.86(20.79) \\
5(9.26) \\
5(0.0) \\
5.88(1.89) \\
1.01(0.07)\end{array}$ & $\begin{array}{l}0.23 \\
0.66 \\
0.59 \\
0.46 \\
1.00 \\
0.69 \mathrm{~b} \\
0.47\end{array}$ \\
\hline $\begin{array}{l}\text { Comorbidities (n/\%) } \\
\text { None } \\
\text { One to three } \\
\text { (DM. HBP. Dyslipidemia) }\end{array}$ & $\begin{array}{c}5(29.4) \\
12(70.6)\end{array}$ & $\begin{array}{l}2(22.2) \\
7(77.8)\end{array}$ & $\begin{array}{l}3(37.5) \\
5(62.5)\end{array}$ & $0.62^{\mathrm{a}}$ \\
\hline
\end{tabular}

aPearson's chi-square; 'Mann-Whitney test; $\mathrm{SaO}_{2}$, arterial partial oxygen pressure; $\mathrm{CPB}$, cardiopulmonary bypass; DM, diabetes melitus; HBP, high blood pressure; Intraop, intraoperative; postop, postoperative; NMB, neuromuscular blocker. 
significant associations with the type of mechanical ventilator used $(\mathrm{p}=1.00)$ by a binomial test comparing the proportions of patients ventilated in either one of the ventilators available. Out of the cases with AIt of $10 \%$ or higher $(n=16)$, thirteen occurred under the use of Savina ventilator and three of them under Engstrom ventilator. Out of the cases with AIt lower than $10 \%(n=7)$, six occurred under the use of Savina ventilator and one under the Engstrom ventilator. The odds of AIt of $10 \%$ or higher were higher in the VCV group compared to the PCV [VCV 146 (75.6\%) vs PCV 47 (24.4\%), OR 3.46 (1.97-6.07); $p<0.001]$. (Figure 4). Regarding the assisted breathing phases, group-independently, the AIt of $10 \%$ or higher was more likely to occur during $\mathrm{T} 1$ than in $\mathrm{T} 2$ (T1: $86(70.5 \%) v s$ T1). T2: 36 (29.5\%), OR 3.85 (1.9-7.79); $p<0.001$. Between the two phases of spontaneous breathing (T2 and T3), the AIt presents a higher chance of severity in phase T3 [T2: 36 (33.6\%) vs T3: 71 (66.4\%), OR 0.47 (0.24-0.91); $\mathrm{p}=0.025]$ (Figure 4). When analyzing the severity of the AIt in both groups and in all phases, we observed that the odds for an AIt of $10 \%$ or higher were higher in patients initially ventilated at VCV within all phases [OR 2.79 (1.36-5.73) between $\mathrm{T} 1$ and $\mathrm{T} 2$; $\mathrm{p}=0.005$, OR 2.61 (1.27-5.37) between T1 and T3; $\mathrm{p}=0.009$ and OR 4.99 (2.37-10.37) between $\mathrm{T} 2$ and T3; $p<0.001$ ] (Figure 4). In relation to the AI by types of asynchronies, double triggering and early cycling were the most frequent and with greater magnitude in the groups, whereas autotriggering and late cycling were not detected. Both in inter-group and in intra-phases analysis, there were no significant differences for the specific AI (Table 4).

\section{Discussion}

The main findings in this study were: i) the visual inspection method proved to be reliable for the detection of patient-ventilator asynchrony with strong correlation and high inter-rater agreement; ii) There was a high number of patients who presented asynchrony

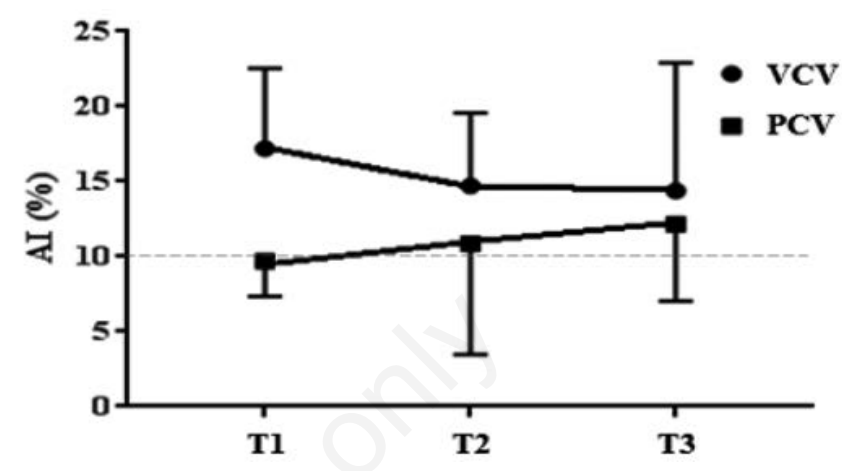

Figure 3. AItotal index over the three ventilatory time-points between VCV and PCV groups.

Table 2. Monitoring parameters of ventilation and oxygenation.

\begin{tabular}{|c|c|c|c|c|c|c|c|}
\hline Initial mode & $\begin{array}{l}\text { Ventilatory } \\
\text { phases }\end{array}$ & $\begin{array}{l}\text { VCe/kg } \\
(\mathrm{ml} / \mathrm{Kg})\end{array}$ & $\begin{array}{c}\text { FR } \\
(\mathrm{rpm})\end{array}$ & $\begin{array}{l}\mathrm{T} \text { insp } \\
(\mathrm{s})\end{array}$ & $\mathrm{pH}$ & $\mathrm{PaCO}_{2}(\mathrm{mmHg})$ & $\mathrm{PaO}_{2} / \mathrm{FiO}_{2}$ \\
\hline VCV & $\begin{array}{l}\text { T1 }(n=9) \\
\text { T2 }(n=9) \\
\text { T3 }(n=9)\end{array}$ & $\begin{array}{c}8.9(2.5) \\
10.2(2.7) \\
9(3.3)\end{array}$ & $\begin{array}{l}17.8(4.4) \\
14.8(2.7) \\
15.7(3.0)\end{array}$ & $\begin{array}{l}0.99(0.07) \\
1.29(0.14) \\
1.33(0.17)\end{array}$ & $\begin{array}{l}7.38(0.1) \\
7.36(0.1) \\
7.33(0.6)\end{array}$ & $\begin{array}{l}38.9(7.2) \\
38.3(3.0) \\
39.0(6.0)\end{array}$ & $\begin{array}{l}356.5(91.7) \\
398.9(87.9) \\
381.6(73.8)\end{array}$ \\
\hline PCV & $\begin{array}{l}\text { T1 }(n=8) \\
\text { T2 }(n=8) \\
\text { T3 }(n=8)\end{array}$ & $\begin{array}{c}8.7(1.3) \\
8.7(1.3) \\
8.9(2)\end{array}$ & $\begin{array}{l}16.9(2.1) \\
15.8(2.5) \\
16.8(4.0)\end{array}$ & $\begin{array}{c}1.01(0.07) \\
1.14(0.14) \\
1.2(0.13)\end{array}$ & $\begin{array}{l}7.30(0.1) \\
7.33(0.1) \\
7.36(0.1)\end{array}$ & $\begin{array}{l}40.6(6.0) \\
39.3(3.7) \\
36.8(2.8)\end{array}$ & $\begin{array}{l}375.6(91.4) \\
346.7(45.3) \\
360.2(63.6)\end{array}$ \\
\hline$p$ & $\begin{array}{l}\text { Intergroup }^{\mathrm{a}} \text { VCV x PCV } \\
\text { Inter-phase }^{\mathrm{b}} \\
\text { T1 x T2 } \\
\text { T1 x T3 } \\
\text { T2 x T3 } \\
\text { Interaction }{ }^{\mathrm{b}} \text { group-phase }\end{array}$ & $\begin{array}{l}0.20 \\
0.57 \\
0.48 \\
0.89\end{array}$ & $\begin{array}{l}0.09 \\
0.21 \\
0.64 \\
0.45\end{array}$ & $\begin{array}{c}<0.001 \\
<0.001 \\
0.26 \\
0.13\end{array}$ & $\begin{array}{l}0.88 \\
0.76 \\
0.89 \\
0.09\end{array}$ & $\begin{array}{l}0.72 \\
0.38 \\
0.62 \\
0.66\end{array}$ & $\begin{array}{l}0.95 \\
0.66 \\
0.62 \\
0.38\end{array}$ \\
\hline
\end{tabular}

aStudent $t$-test; btwo-factor ANOVA test; Paw, airway pressure; Ppeak, peak pressure; Vte/kg, tidal volume/predicted body weight; PaCO ${ }_{2}$, arterial partial pressure of carbon dioxide; PaO ${ }_{2}$, arterial partial oxygen pressure; $\mathrm{FiO}_{2}$, inspired oxygen fraction.

Table 3. Comparison of severity scores and respiratory variables between AI cut-off points.

\begin{tabular}{lccc} 
Variables & $\mathbf{A I}_{\mathbf{t}}<\mathbf{1 0} \%(\mathbf{n = 7})$ & $\mathbf{A I}_{\mathbf{t}} \geq \mathbf{1 0} \%(\mathbf{n}=\mathbf{1 6})$ & $\boldsymbol{p}$ \\
EuroScore II & $1.5(2.12)$ & $2.71(1.8)$ & 0.46 \\
$\mathrm{~V}_{\mathrm{t}}(\mathrm{ml} / \mathrm{PBW})$ & $10.52(3.27)$ & $9.25(2.12)$ & 0.29 \\
$\mathrm{RR}(\mathrm{ipm})$ & $16.57(2.15)$ & $15.06(2.11)$ & 0.20 \\
Tins $(\mathrm{s})$ & $1.13(0.17)$ & $1.18(0.2)$ & 0.63 \\
$\mathrm{pH}$ & $7.34(0.04)$ & $7.37(0.07)$ & 0.34 \\
$\mathrm{PaCO}_{2}(\mathrm{mmHg}) \mathrm{b}$ & $39.4(4.44)$ & $41.16(5.9)$ & 0.48 \\
$\mathrm{PaO}_{2} / \mathrm{FiO}_{2} \mathrm{~b}$ & $357.28(48.3)$ & $371.16(86.3)$ & 0.46 \\
\hline
\end{tabular}

${ }^{\mathrm{b}}$ Mann-Whitney test. 
with the ventilator at some point during the immediate postoperative period, although compared to the total number of ventilatory cycles their percentage of asynchronous cycles was low; iii) The presence of asynchrony and AIt $\geq 10 \%$ was not influenced by clinical severity and did not lead to alterations in oxygenation and ventilation, and there were no cases of weaning failure; iv) The chance of AIt $\geq 10 \%$ was higher in VCV ventilation than in PCV, and it maintains in the following PSV phases; and v) double triggering and early cycling were the most common and with the highest indexes with short-term mechanical ventilation.

\section{Offline asynchrony detection method application}

The most advanced asynchrony detection methods include automatic detection software [13,29-31] and semi-invasive methods [14,32-36], which allow more accurate monitoring of the interaction between mechanical ventilators and patients by capturing signals of diaphragmatic activity during the inspiratory effort Even so, the advanced methods have their limitations for use in clinical practice.

Software limitations are usually research-purpose-only application and also dependent on determined mechanical ventilators models. Meanwhile, the semi-invasive methods require professional expertise for adequate catheter positioning in order to ensure accurate functioning and reliability on the graphics capture. Another problem is the high-price of both set of methods, which makes them unfeasible for daily clinical practice [20,29,31].

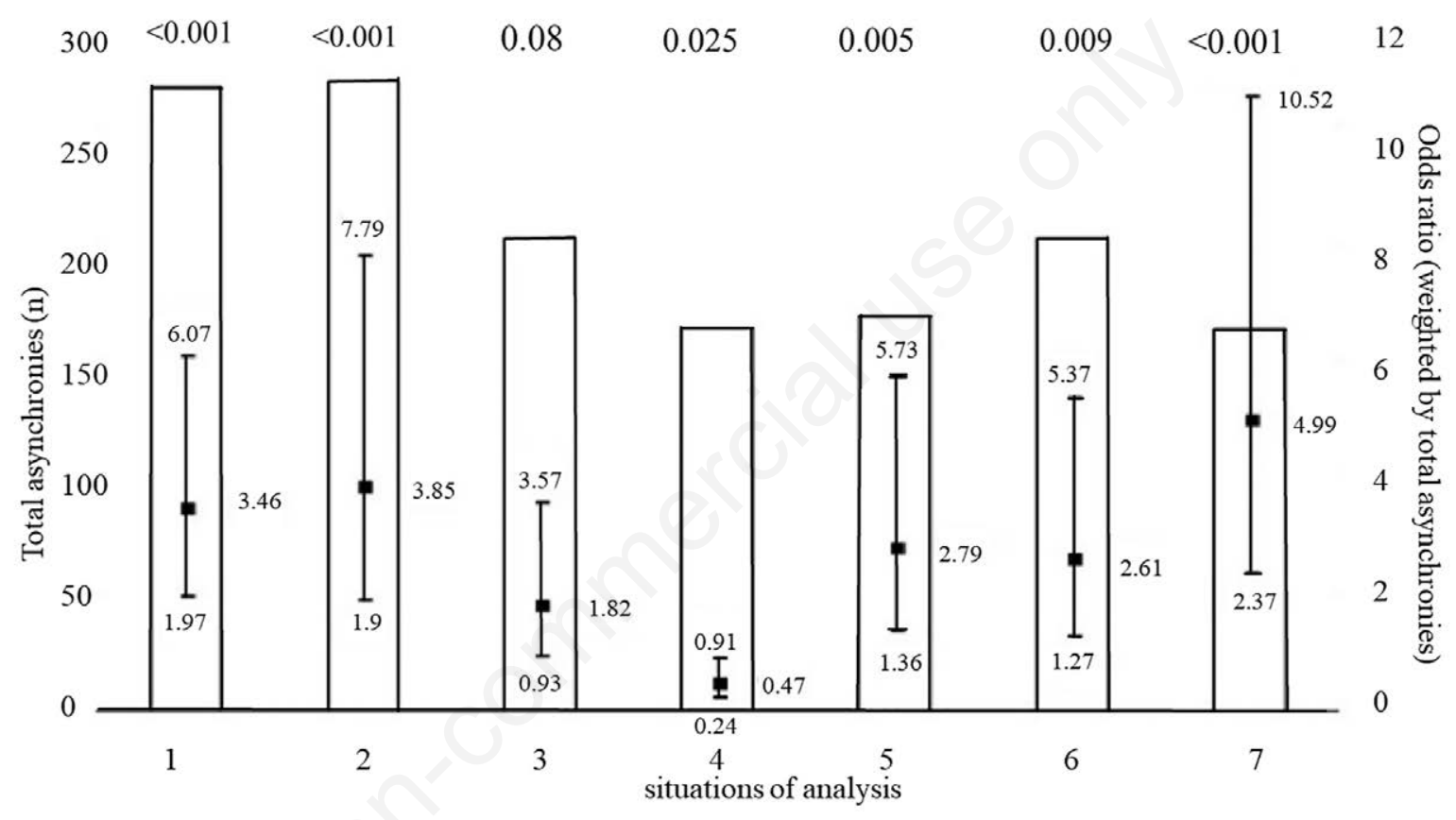

Figure 4. Total asynchronies and Odds ratio weighed by AI with their respective confidence intervals. Situation analysis: 1 , VCV x PCV modes; 2, T1 $x$ T2 phases; 3, T1 $x$ T3 phases; 4 , T2 $x$ T3 phases; 5, VCV $x$ PCV in T1-T2 strata; 6, VCV $x$ PCV in T1-T3 strata; 7, VCV $x$ PCV in T2-T3 strata.

Table 4. Specific asynchrony indexes by modes and phases.

\begin{tabular}{|c|c|c|c|c|c|c|}
\hline Initial mode & Phase & $\mathbf{A I}_{\mathrm{t}}$ & IIE & DT & EC & IEE \\
\hline VCV & $\begin{array}{l}\text { T1 }(n=5) \\
\text { T2 }(n=3) \\
\text { T3 }(n=6)\end{array}$ & $\begin{array}{c}17.20(5.35) \\
14.7(4.8) \\
14.39(8.5)\end{array}$ & $\begin{array}{c}- \\
3 \\
1.25(0.5)\end{array}$ & $\begin{array}{c}10.75(5.37) \\
4(1.41) \\
8.83(12.35)\end{array}$ & $\begin{array}{c}6 \\
2.67(1.15) \\
3.75(3.1)\end{array}$ & $\begin{array}{c}2 \\
1.5(0.71) \\
-\end{array}$ \\
\hline PCV & $\begin{array}{l}\text { T1 }(n=4) \\
\text { T2 }(n=3) \\
\text { T3 }(n=2)\end{array}$ & $\begin{array}{c}9.75(2.34) \\
10.86(7.36) \\
12.16(5.13)\end{array}$ & $\begin{array}{l}1 \\
- \\
1\end{array}$ & $\begin{array}{l}4.5(4.95) \\
2.3(1.53) \\
3.5(0.71)\end{array}$ & $\begin{array}{c}2.5(0.71) \\
2(1.41) \\
-\end{array}$ & $\begin{array}{c}6 \\
10 \\
4(1.4)\end{array}$ \\
\hline$p$ & $\begin{array}{l}\text { Inter-group VCV x PCV } \\
\text { Inter-phases } \\
\text { T1 x T2 } \\
\text { T1 x T3 } \\
\text { T2 x T3 } \\
\text { Interaction group-phase }\end{array}$ & $\begin{array}{l}0.37 \\
\\
0.96 \\
0.22 \\
0.26 \\
0.64\end{array}$ & $\begin{array}{c}0.67 \\
1.00 \\
- \\
- \\
0.87\end{array}$ & $\begin{array}{l}0.46 \\
\\
0.56 \\
0.68 \\
0.97 \\
0.74\end{array}$ & $\begin{array}{l}0.53 \\
\\
0.33 \\
0.70 \\
0.29 \\
0.24\end{array}$ & $\begin{array}{l}0.06 \\
\\
0.15 \\
0.50 \\
0.10 \\
0.24\end{array}$ \\
\hline
\end{tabular}

Altotal, total asynchrony index; IIE, ineffective inspiratory effort; DT, double-triggering; EC, early cycling; IEE, ineffective expiratory effort; RT, reverse triggering; ANOVA two-way. 
The method of visual inspection is acceptable for asynchrony diagnosis and thus helps to take the measures of correcting it. The results of Thille et al. [20] on evaluating this method by two assessors showed good reproducibility due to the strong and significant correlation $(\mathrm{n}=62, \rho=0.94, p<0.01)$ and high agreement $(\kappa$ value $0.96, p<0.01)$ in long-term patients under mechanical ventilation. These results were similar to ours.

According to Kottner et al., despite varying according to aim, diagnoses and estimated margin of error for decision-making, values of at least 0.60 for intra-class coefficient are an acceptable level of reliability for a method of evaluation [30]. Thus, we consider that the method of visual inspection adopted for this study is reliable for the detection of asynchrony. However, we recognize that the analysis may be underestimated in relation to semi-invasive methods [37].

\section{Asynchronies incidence and impact in clinical outcomes}

In our findings around $80 \%$ of the patients presented some type of asynchrony, and this was similar to other studies, although their patients were non-surgical. Kuo et al. [37] reported an incidence of asynchrony of $87 \%$ and Fabry et al. [38] detected $81 \%$, both with the majority of patients having COPD. De Wit et al. [39] detected $85 \%$ in patients with ARF mainly due to pneumonia [38-40]. In these studies, they appeared as factors associated with the incidence of asynchrony to the hyperinflated lung condition of some patients and deep sedation. Our incidence rate was lower compared to other studies such as Chao et al. [41], who detected $10.9 \%$ in chronically ill patients in prolonged mechanical ventilation weaning, Robinson et al. It is noteworthy that, although the incidence was high, it had a small magnitude with only $7 \%$ of asynchronous cycles, and no repercussions were observed for oxygenation and ventilation. Some studies report associations of asynchronous cycles with the worst prognosis in clinical outcomes, such as longer mechanical ventilation [34], higher incidence of tracheostomy [35], longer ICU stay, and hospital mortality [44-47]. Others suggested associations between the high prevalence of asynchrony and changes in physiological variables, such as ventilation and oxygenation, described in the literature as influencing the severity of the asynchrony index. The study by Thille et al. [20] analyzed 62 patients with no specific profile with duration of mechanical ventilation of around 10 days, who were able to trigger assisted breaths or to maintain themselves in the spontaneous breaths. The ventilation variables (tidal volume, respiratory rate and $\mathrm{PaCO}_{2}$ ) and oxygenation $\left(\mathrm{PaO}_{2} / \mathrm{FIO}_{2}\right)$ among patients with or without critical asynchrony index did not differ. The same result was observed by Rolland-Debord et al. [47], who assessed tidal volume by predicted body weight, respiratory rate, $\mathrm{PaCO}_{2}$, and oxygenation index in a study of 103 patients intubated for different etiologies of acute respiratory failure with mean time of invasive mechanical ventilation between 10 and 12 days $[35,37,44]$.

\section{Asynchrony index - severity indicator}

The frequency of asynchrony is measured by the asynchrony index obtained by the ratio between cycles with asynchrony and the total of all cycles. From Thille's study [20], 10\% or more was marked as a cutoff point because it was associated with worse clinical outcomes. This reference parameter was adopted in the other studies on patient-ventilator asynchrony [40,44-50].The fact that the highest incidence of total AI of $10 \%$ or higher occurs in VCV ventilation may be related to the characteristic of the mode that promotes constant volume delivery, in contrast to the physiological process, in which the inspired volume varies with every breath. Many asynchronies probably occurred when the volume delivered was not adequate for the need in certain cycles, whereas in PCV these moments were less frequent because the volume varies accordingly to the respiratory mechanics $[45,46]$. Disregarding the initial ventilation mode, the critical AI $(\mathrm{AI} \geq 10)$ was higher during assist-controlled cycles compared to cycles predominantly spontaneous, which was also observed by Thille and Chanques [20,51]. However, their patients had a time of mechanical ventilation longer than $20 \mathrm{~h}$. It is believed that asynchrony influencing factors in patients under shortterm mechanical ventilation, such as surgical ones, differ from those in mechanical ventilation for clinical diseases reasons. There was a higher frequency of critical AI during the pre-extubation period (T3) than in the transition phase of A/C to PSV (T2). Patients submitted to low parameters may not have their metabolic needs attended to during this phase of assessing their readiness for extubation [47]. With underassistance of ventilation, patients are forced to increase their respiratory work and lung volumes, consequently they present a greater magnitude of asynchrony, among them double triggering and associated stacking [48].

\section{Types of asynchronies detected}

Studies have pointed out that ineffective effort during the expiratory phase is usually associated to reasons such as abnormal respiratory mechanics, reduced respiratory drive induced by deep sedation, and poor adjustment in ventilator parameters [38,49-53]. Its occurrence is common in clinical patients with respiratory muscle strength deficit, which makes inspiratory triggering difficult and thus prone to difficult weaning. After ineffective inspiratory efforts, early cycling and double triggering are the most common asynchronies, as reported by Thille et al. and de Wit et al. [20,39]. The harmony between ventilator and neural time adjustment is difficult since the patient's neural time is not always constant with the setting on the ventilator. Previous studies also point out that the double-triggered cycles are directly proportional to the respiratory drive $[51,54,55]$.

Patients with normal lung mechanics, as expected in our sample with no history of lung disease, are more likely to develop cycling asynchrony, mainly early cycling that can usually result in double triggering. These patients who experience this asynchrony suffer from greater energy expenditure because they have to "fight" against an obligation imposed by the ventilator that does not meet their need at the moment and may affect their clinical prognosis [55]. The relationship between the two types of asynchrony is intimate because it depends on the degree of inspiratory muscle effort, so that when "weak" in response to the premature opening of the ventilator exhalation valve in relation to neural time, early cycling asynchrony occurs. However, the continuity of the inspiratory effort after the opening of the exhalation valve can again activate the triggering, and thus a second cycle is triggered with a short expiratory period between both. As described in the literature [56,57], inadequate tidal volume and inspiratory time are common causes of asynchrony, especially when there is greater autonomy of spontaneous effort. Inspiratory times were similar in patients either ventilated in VCV or PCV modes and it increased when ventilated in PSV mode. Unlike previous modes, inspiratory efforts are greater in this mode that allows for greater patient autonomy, so inspiratory time is no longer directly mechanically controlled $[58,59]$. In the study, two mechanical ventilators from different manufacturers were used, with operating characteristics with small differences. We believe that this did not influence the results since the asynchrony indices did not differ in the analysis stratified by the manufacturer of the mechanical ventilator.

\section{Methodological limitations}

Some limitations to be considered are that our results are based on a selected population profile, less than 65 years of age, not obese, with low risk for the severity score, who had undergone elective surgeries, and had no history of pulmonary disease. We did not evaluate respiratory function and muscular strength in the presurgical period, which are factors associated to the presence of 
asynchrony. In future studies, it would be interesting to verify whether the implications observed in this study apply to obese cardiac post-operative patients, who were older, had been on mechanical ventilation for a longer period, or had postoperative complications, since we noticed a larger number of these patients, who ended up being excluded from our study because they were not covered by our criteria.

There is a high presence of asynchrony, and in most cases with critical asynchrony index in surgical patients, although we cannot extrapolate the results to more severe clinical conditions. The method of visual inspection, although reliable and reproducible, is done offline, allowing reanalysis, which in clinical practice is not possible. This offline method is time-consuming, requiring expertise not only to recognize and classify changes in curves but also to handle the files to be analyzed later.

\section{Clinical implications}

In view of this high presence of asynchrony and a significant incidence of asynchrony index of $10 \%$ or greater, it is necessary to reinforce that the ICU healthcare professionals involved in the management of mechanical ventilation be better aware of monitoring these events and minimizing them for improved clinical prognosis. In these patients, PCV ventilation seems to be better because it had a lower chance of a critical asynchrony index, besides the additional advantage of preventing pulmonary complications due to unregulated pressure. We concluded that there is a high incidence of patients with asynchrony at some time during the short period of mechanical ventilation in the postoperative period although with a low incidence of asynchronous cycles, with emphasis on early cycling and double firing. The VCV mode presented a higher chance of the occurrence of critical asynchrony index remaining during the prospective phases towards weaning.

\section{List of abbreviations}

$\begin{array}{ll}\text { AIspecific } & \text { asynchrony index specific } \\ \mathrm{AIt} & \text { asynchrony index total } \\ \mathrm{CPB} & \text { cardiopulmonary bypass } \\ \mathrm{DC} & \text { delayed cycling } \\ \mathrm{DM} & \text { diabetes mellitus } \\ \mathrm{DT} & \text { double triggering } \\ \mathrm{EC} & \text { early cycling } \\ \mathrm{EIT} & \text { electrical impedance tomography } \\ \mathrm{FiO} & \text { inspired fraction of oxygen } \\ \mathrm{HBP} & \text { high blood pressure } \\ \mathrm{HR} & \text { heart rate } \\ \mathrm{ICU} & \text { intensive care unit } \\ \mathrm{IEE} & \text { expiratory ineffective effort } \\ \mathrm{IIE} & \text { inspiratory ineffective effort } \\ \mathrm{NMB} & \text { neuromuscular blocking } \\ \mathrm{PaCO} & \text { arterial partial pressure of carbon dioxide } \\ \mathrm{PaO} & \text { arterial partial pressure of oxygen } \\ \mathrm{Paw} & \text { airway pressure } \\ \mathrm{PCV} & \text { pressure-controlled ventilation } \\ \mathrm{PEEP} & \text { positive end-expiratory pressure } \\ \mathrm{PSV} & \text { pressure support ventilation } \\ \mathrm{PVA} & \text { patient-ventilator asynchrony } \\ \mathrm{RR} & \text { respiratory rate } \\ \mathrm{RT} & \text { reverse triggering } \\ \mathrm{SaO} & \text { arterial partial pressure of oxygen } \\ \mathrm{SpO} & \text { peripheral oxygen saturation } \\ \mathrm{Tins}_{\mathrm{VCV}} & \text { inspiratory time } \\ \mathrm{Vte} & \text { volume-controlled ventilation } \\ & \text { expired tidal volume }\end{array}$

\section{References}

1. Ranucci M, Bellucci C, Conti D, Cazzaniga A, Maugeri B. Determinants of Early discharge from the intensive care unit after cardiac operations. Ann Thorac Surg 2007;83:1089-95.

2. Johnson D, Kelm C, To T, Hurst T, Naik C, Gulka I, et al. Postoperative physical therapy after coronary artery bypass surgery. Am J Respir Crit Care Med 1995;152:953-8.

3. Brown CH. Delirium in the cardiac surgical ICU. Curr Opin Anaesthesiol 2014;27:117-22.

4. Jung P, Pereira MA, Hiebert B, Song X, Rockwood K, Tangri $\mathrm{N}$, et al. The impact of frailty on postoperative delirium in cardiac surgery patients. J Thorac Cardiovasc Surg 2015;149:869-75.

5. Rudolph JL, Jones RN, Levkoff SE, Rockett C, Inouye SK, Sellke FW, et al. Derivation and validation of a preoperative prediction rule for delirium after cardiac surgery. Circulation 2009;19:229-36.

6. Gajic O, Dabbagh O, Park PK, Adesanya A, Chang SY, Hou $\mathrm{P}$, et al. Early identification of patients at risk of acute lung injury: Evaluation of lung injury prediction score in a multicenter cohort study. Am J Respir Crit Care Med 2011;83:46270 .

7. Kor DJ, Lingineni RK, Gajic O, Park PK, Blum JM, Hou PC, et al. Predicting risk of postoperative lung injury in high-risk surgical patients: A multicenter cohort study. Anesthesiology 2014;120:1168-81.

8. Stephens RS, Shah AS, Whitman GJR. Lung injury and acute respiratory distress syndrome after cardiac surgery. Ann Thorac Surg 2013;95:1122-9.

9. Sengupta S. Post-operative pulmonary complications after thoracotomy. Indian J Anaesth 2015;59:618-26.

10. Bouadma L, Sonneville R, Garrouste-Orgeas M, Darmon M, Souweine B, Voiriot $G$, et al. Ventilator-associated events: Prevalence, outcome, and relationship with ventilator-associated pneumonia. Crit Care Med 2015;43:1798-806.

11. Meagher AD, Lind M, Senekjian L, Iwuchukwu C, Lynch JB, Cuschieri J, et al. Ventilator-associated events, not ventilatorassociated pneumonia, is associated with higher mortality in trauma patients. J Trauma Acute Care Surg 2019;87:307-14.

12. Blanch L, Villagra A, Sales B, Montanya J, Lucangelo U, Luján $\mathrm{M}$, et al. Asynchronies during mechanical ventilation are associated with mortality. Intensive Care Med 2015;41:633-41.

13. Blanch L, Sales B, Montanya J, Lucangelo U, Oscar GE, Villagra A, et al. Validation of the Better Care ${ }^{\circledR}$ system to detect ineffective efforts during expiration in mechanically ventilated patients: A pilot study. Intensive Care Med 2012;38:772-80.

14. Mulqueeny Q, Ceriana P, Carlucci A, Fanfulla F, Delmastro M, Nava S. Automatic detection of ineffective triggering and double triggering during mechanical ventilation. Intensive Care Med 2007;33:2014-8.

15. Pham T, Telias I, Piraino T, Yoshida T, Brochard LJ. Asynchrony consequences and management. Crit Care Clin 2018;34:325-41.

16. Georgopoulos D, Prinianakis G, Kondili E. Bedside waveforms interpretation as a tool to identify patient-ventilator asynchronies. Intensive Care Med 2006;32:34-47.

17. Nieuwenhuijs D, Bruce J, Drummond GB, Warren PM, Wraith PK, Dahan A. Ventilatory responses after major surgery and high dependency care. Br J Anaesth 2012;108:86471.

18. Imanaka H, Nishimura M, Takeuchi M, Kimball WR, Yahagi N, Kumon K. Autotriggering caused by cardiogenic oscilla- 
tion during flow-triggered mechanical ventilation. Crit Care Med 2000;28:402-7.

19. Vitale V, Ricci Z, Morelli S, Giorni C, Testa G, Di Chiara L, et al. Neurally adjusted ventilatory assist and lung transplant in a child: A case report. Pediatr Crit Care Med 2010;11:e4851.

20. Thille AW, Rodriguez P, Cabello B, Lellouche F, Brochard L. Patient-ventilator asynchrony during assisted mechanical ventilation. Intensive Care Med 2006;32:1515-22.

21. Mellott KG, Grap MJ, Munro CL, Sessler CN, Wetzel PA, Nilsestuen JO, et al. Patient ventilator asynchrony in critically ill adults: Frequency and types. Heart Lung J Acute Crit Care 2014;43:231-43

22. Dres M, Rittayamai N, Brochard L. Monitoring patient-ventilator asynchrony. Curr Opin Crit Care 2016;22:246-53.

23. Toomasian CJ, Aiello SR, Drumright BL, Major TC, Bartlett RH, Toomasian JM. The effect of air exposure on leucocyte and cytokine activation in an in-vitro model of cardiotomy suction. Perfusion 2018;33:538-45.

24. Carrel T. Early extubation: A proposed new metric or what was first: The egg or the chicken? Semin Thorac Cardiovasc Surg 2016;28:300-1.

25. Crawford TC, Magruder JT, Grimm JC, Sciortino C, Conte JV, Kim BS, et al. Early extubation: A proposed new metric. Semin Thorac Cardiovasc Surg 2016;28:290-9.

26. Heringlake M, Nowak Y, Schön J, Trautmann J, Berggreen $\mathrm{AE}$, Charitos EI, et al. Postoperative intubation time is associated with acute kidney injury in cardiac surgical patients. Crit Care 2014;18:547.

27. Kotfis K, Szylińska A, Listewnik M, Lechowicz K, Kosiorowska M, Drożdżal S, et al. Balancing intubation time with postoperative risk in cardiac surgery patients - A retrospective cohort analysis. Ther Clin Risk Manag 2018;14:2203-12.

28. Muller Moran H, Maguire D, Maguire D, Kowalski S, Jacobsohn E, Mackenzie G, et al. Effect of earlier extubation on post-operative delirium after coronary artery bypass grafting. J Thorac Cardiovasc Surg 2019;33:S92.

29. Chen CW, Lin WC, Hsu CH, Cheng KS, Lo CS. Detecting ineffective triggering in the expiratory phase in mechanically ventilated patients based on airway flow and pressure deflection: Feasibility of using a computer algorithm. Crit Care Med 2008;36:455-61.

30. Kottner J, Audige L, Brorson S, Donner A, Gajewski BJ, Hroóbjartsson A, et al. Guidelines for Reporting Reliability and Agreement Studies (GRRAS) were proposed. Int J Nurs Stud 2011;48:661-71.

31. Nashef SAM, Roques F, Michel P, Gauducheau E, Lemeshow S, Salamon R. European system for cardiac operative risk evaluation (EuroSCORE). Eur J Cardio-thoracic Surg 1999;16:9-13.

32. Sinderby C, Liu S, Colombo D, Camarotta G, Slutsky AS, Navalesi $P$, et al. An automated and standardized neural index to quantify patient-ventilator interaction. Crit Care 2013; 17:R239.

33. García-Raimundo M, Fraga R, Saz T, Aguilar G, Martí F, Belda FJ, Maruenda A. [Comparison of patient-ventilator synchronization during pressure support ventilation versus amplified spontaneous pattern in postoperative patients].[Article in Spanish]. Rev Esp Anestesiol Reanim 2000;47:235-44.

34. Navalesi P, Colombo D, Cammarota G, Vaschetto R. Neurally adjusted ventilatory assist. Eur Respir Monogr 2012;55:116-23.

35. De Wit M, Miller KB, Green DA, Ostman HE, Gennings C, Epstein SK. Ineffective triggering predicts increased duration of mechanical ventilation. Crit Care Med 2009;37:740-5.

36. Piquilloud L, Jolliet P, Revelly J-P. Automated detection of patient-ventilator asynchrony: new tool or new toy? Crit Care 2013;17:1015.

37. Kuo NY, Tu ML, Hung TY, Liu SF, Chung YH, Lin MC, et al. A randomized clinical trial of neurally adjusted ventilatory assist versus conventional weaning mode in patients with COPD and prolonged mechanical ventilation. Int J COPD 2016;11:945-51.

38. Fabry B, Guttmann J, Eberhard L, Bauer T, Haberthur C, Wolff G. An analysis of desynchronization between the spontaneously breathing patient and ventilator during inspiratory pressure support. Chest 1995;107:1387-94.

39. De Wit M, Miller KB, Green DA, Ostman HE, Gennings C, Epstein SK. Ineffective triggering predicts increased duration of mechanical ventilation. Crit Care Med 2009;37:2740-5.

40. de Wit M, Pedram S, Best AM, Epstein SK. Observational study of patient-ventilator asynchrony and relationship to sedation level. J Crit Care 2009;24:2774-80.

41. Chao DC, Scheinhorn DJ, Stearn-Hassenpflug M. Patientventilator trigger asynchrony in prolonged mechanical ventilation. Chest 1997;112:1592-99.

42. Robinson BR, Blakeman TC, Toth P, Hanseman DJ, Mueller E, Branson RD. Patient-Ventilator asynchrony in a traumatically injured population. Respir Care 2013;58:1847-55.

43. Branson RD, Blakeman TC, Robinson BRH. Asynchrony and dyspnea. Respir Care 2013;58:973-89.

44. Sasaki N, Meyer MJ, Eikermann M. Postoperative respiratory muscle dysfunction: Pathophysiology and preventive strategies. Anesthesiology 2013;118:961-78.

45. Gutierrez G, Ballarino GJ, Turkan H, Abril J, De La Cruz L, Edsall C, et al. Automatic detection of patient-ventilator asynchrony by spectral analysis of airway flow. Crit Care 2011;15:R167.

46. Demoule A, Clavel M, Rolland-Debord C, Perbet S, Terzi N, Kouatchet A, et al. Neurally adjusted ventilatory assist as an alternative to pressure support ventilation in adults: a French multicentre randomized trial. Intensive Care Med 2016;42:1723-32.

47. Rolland-Debord C, Bureau C, Poitou T, Belin L, Clavel M, Perbet $\mathrm{S}$, et al. Prevalence and prognosis impact of patientventilator asynchrony in early phase of weaning according to two detection methods. Anesthesiology 2017;27:989-97.

48. Navalesi P, Longhini F. No harm, no benefit: should we give up with neurally adjusted ventilatory assist? Intensive Care Med 2016;42:1770-1.

49. Koh SO. Mode of mechanical ventilation: Volume controlled mode. Crit Care Clin 2007;23:161-7.

50. Nichols D, Haranath S. Pressure Control Ventilation. Crit Care Clin 2007;23:183-99.

51. Chanques G, Kress JP, Pohlman A, Patel S, Poston J, Jaber S, et al. Impact of ventilator adjustment and sedation-analgesia practices on severe asynchrony in patients ventilated in assist-control mode. Crit Care Med 2013;41:2177-87.

52. Schmidt M, Demoule A, Polito A, Porchet R, Aboab J, Siami $\mathrm{S}$, et al. Dyspnea in mechanically ventilated critically ill patients. Crit Care Med 2011;39 2059-65.

53. Esteban A, Anzueto A, Alía I, Gordo F, Apezteguía C, Pálizas $\mathrm{F}$, et al. How is mechanical ventilation employed in the intensive care unit? An international utilization review. Am J Respir Crit Care Med 2000;161:1450-8.

54. Purro A, Appendini L, De Gaetano A, Gudjonsdottir M, Donner CF, Rossi A. Physiologic determinants of ventilator dependence in long-term mechanically ventilated patients. Am J Respir Crit Care Med 2000;161:1115-23.

55. Nava S, Bruschi C, Fracchia C, Braschi A, Rubini F. Patient- 
ventilator interaction and inspiratory effort during pressure support ventilation in patients with different pathologies. Eur Respir J 1997;10:177-83.

56. Bassuoni AS, Elgebaly AS, Eldabaa AA, Elhafz AAA. Patient-ventilator asynchrony during daily interruption of sedation versus no sedation protocol. Anesth Essays Res 2012;6:151-6.

57. Chen YH, Yeh MC, Hu HC, Lee CS, Li LF, Chen NH, et al. Effects of lung expansion therapy on lung function in patients with prolonged mechanical ventilation. Can Respir J 2016;2016:5624315.

58. Tokioka H, Tanaka T, Ishizu T, Fukushima T, Iwaki T, Nakamura Y, et al. The effect of breath termination criterion on breathing patterns and the work of breathing during pressure support ventilation. Anesth Analg 2001;92:161-5.

59. Scott K Epstein M. How often does patient-ventilator asynchrony occur and what are the consequences? Respir Care 2011;56:25-38.

Received for publication: 17 February 2020. Accepted for publication: 27 March 2020.

This work is licensed under a Creative Commons Attribution-NonCommercial 4.0 International License (CC BY-NC 4.0).

(C) Copyright: the Author(s), 2020

Licensee PAGEPress, Italy

Multidisciplinary Respiratory Medicine 2020; 15:650

doi:10.4081/mrm.2020.650 